Supporting Information for:

\title{
Effect of side-chain modification on the active layer morphology and photovoltaic performance of liquid crystalline molecular materials
}

Jegadesan Subbiah *, Calvin J. Lee, Valerie D. Mitchell and David J. Jones *

School of Chemistry, Bio21 Institute, University of Melbourne, 30 Flemington Road, Victoria 3010, Australia.

Email: jsubbiah@unimelb.edu.au,djjones@unimelb.edu.au, 


\section{Thin-film fabrication and characterisation}

Samples were prepared for GIWAXS by spin-coating solutions of BTR analogue blends onto PEDOT:PSS coated Si substrates using the same deposition condition and annealing conditions as for the photovoltaic devices. The Si wafers had been sonicated in acetone and isopropanol for 30 minutes each followed by 15 minutes of UV/Ozone treatment. GIWAXS experiments were performed at the Australian Synchrotron on the SAXS/WAXS beamline under ambient conditions. ${ }^{1}$ A Pilatus $200 \mathrm{~K}$ detector was used for 2D diffraction pattern collection. For the neat BTR, BTR-TE and BTR-TIPS films, the energy of the incident beam was $11 \mathrm{kEV}$ at a range of incident angles from $\theta=0.02$ $-0.20^{\circ}$. The sample-to-detector range was $28 \mathrm{~cm}$. For the neat and blend Y6 films, the energy of the incident beam was $12 \mathrm{kEV}$ at a range of incident angles from $\theta=0.11-$ $0.26^{\circ}$. The sample-to-detector range was $68.58 \mathrm{~cm}$. Data from GIWAXS experiments was gathered from the SAXS/WAXS beamline of the Australian Synchrotron and analysed using a customized version of NIKA 2D based in IgorPro. ${ }^{2}$ Atomic force microscopy images were acquired using an Asylum Research Cypher scanning probe microscope operated in tapping mode.

\section{SCLC Mobility Measurements}

The space charge limited current (SCLC) of BTR/BTR-TE/BTR-TIPS were studied using Hole-only and Electron-only devices are fabricated to find the charge-carrier mobilities and the device geometry is in figure S2. From the current density as a function of voltage data, the hole mobility and electron mobility in the space-charge limited current (SCLC) region can be estimated using the Mott-Gurney equation, $J=$ $9\left(\varepsilon_{\mathrm{r}} \varepsilon_{0} \mu\right) / 8 \times\left(\mathrm{V}^{2} / \mathrm{d}^{3}\right)$, where $\mathrm{J}$ is the current density, $\mathrm{V}=\mathrm{V}_{\mathrm{appl}}-\mathrm{V}_{\mathrm{bi}}, \mathrm{V}_{\mathrm{appl}}$ is the applied potential, $\mathrm{V}_{\mathrm{bi}}$ is the built-in potential resulting from workfunction difference between two electrodes, $\varepsilon_{\mathrm{r}}$ is the dielectric constant of the polymer, $\varepsilon_{0}$ is the permittivity of vacuum, $\mu$ is the hole mobility, $d$ is the sample thickness. 

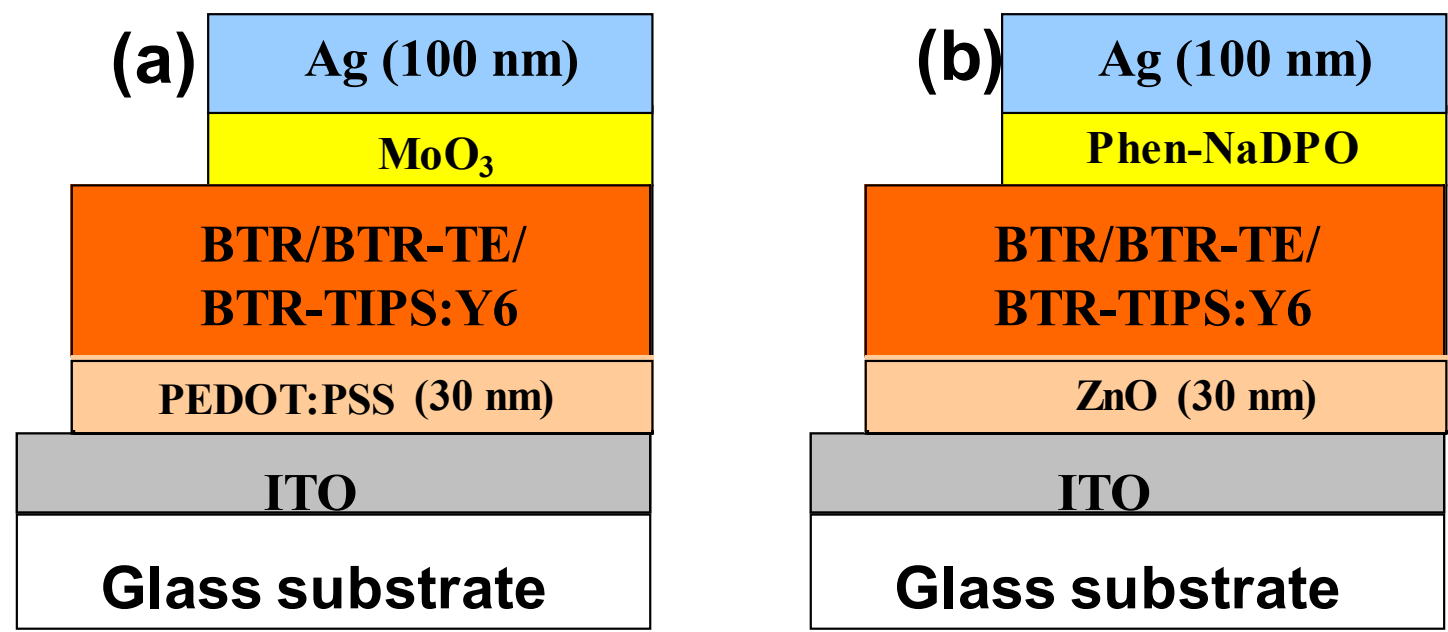

Figure S1. The device structure of (a) Hole-only and (b) Electron-only device.

\section{GIWAX data of pristine film}

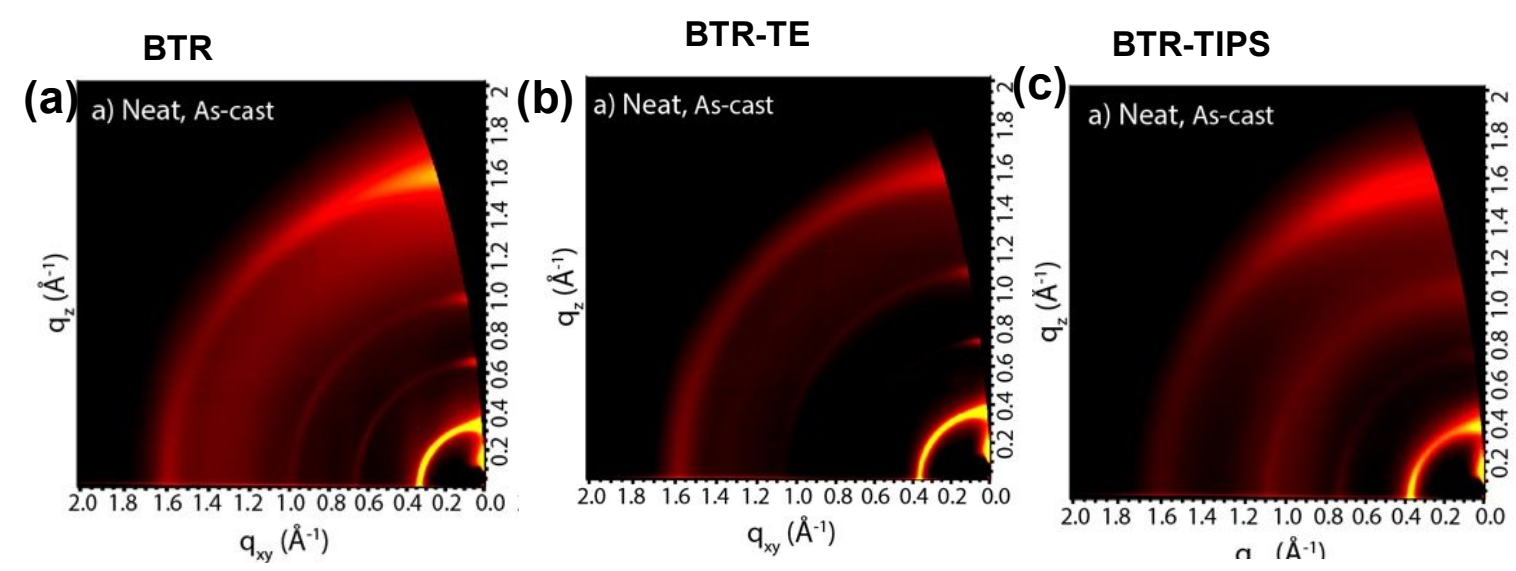

Figure S2. GIWAXS pattern of neat films of (a) BTR, (b) BTR-TE and (c) BTRTIPS.
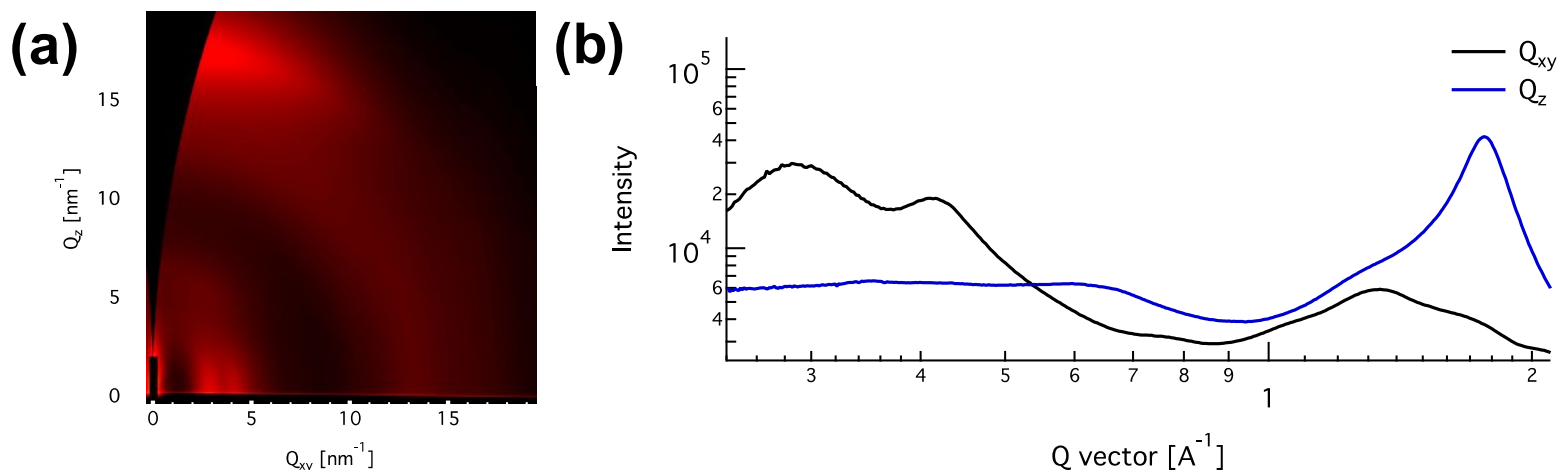

Figure S3. (a) GIWAXS patterns and (b) corresponding scattering profiles of in-plane and out-of-plane for neat Y6 film. 


\begin{tabular}{|c|c|c|c|c|c|c|}
\hline Sample & $\mathbf{q ( 1 0 0 )} \mathbf{n m}^{-\mathbf{1}}$ & $\mathbf{d}(\mathbf{1 0 0}) \mathbf{n m}$ & $\mathbf{C C L} \mathbf{( 1 0 0 )} \mathbf{n m}$ & $\mathbf{s}(\mathbf{1 0 0})$ & $\mathbf{q ( 0 1 0 )} \mathbf{n m}^{-1}$ & $\mathbf{d}(\mathbf{0 1 0}) \mathbf{n m}$ \\
\hline BTR & 3.3 & 1.88 & 29.5 & -0.13 & 16.5 & 0.38 \\
\hline BTR-TE & 3.7 & 1.71 & 27.3 & 0.00 & 16.5 & 0.38 \\
\hline BTR-TIPS & 3.7 & 1.69 & 22.7 & -0.19 & 16.5 & 0.38 \\
\hline BTR:Y6 & 3.4 & 1.86 & 29.8 & -0.19 & 17.0 & 0.37 \\
\hline BTR-TE:Y6 & 3.7 & 1.71 & 25.3 & -0.19 & 17.5 & 0.36 \\
\hline BTR-TIPS:Y6 & 3.9 & 1.61 & 23.9 & 0.71 & 17.5 & 0.36 \\
\hline
\end{tabular}

Table S1. Summary of morphology characteristics calculated from GIWAXS scattering patterns.

\section{OPV device performance of ternary blend}

\begin{tabular}{|c|c|c|c|c|}
\hline Active layer & $\mathbf{J}_{\mathrm{sc}}\left(\mathbf{m A} / \mathbf{c m}^{2}\right)$ & $V_{\text {oc }}(V)$ & FF $(\%)$ & $\begin{array}{l}\text { PCE (\%) } \\
\text { (Best Cell) }\end{array}$ \\
\hline PM6:Y6 (1:1.2) & $24.2 \pm \mathbf{0 . 3 0}$ & $0.83 \pm 0.02$ & $75 \pm \mathbf{3}$ & $\begin{array}{c}14.90 \pm \mathbf{0 . 2 0} \\
\mathbf{( 1 5 . 1 )}\end{array}$ \\
\hline $\begin{array}{c}\text { PM6:Y6 }(0.9: 0.1: 1.2) \\
\text { (BTR 10\%) }\end{array}$ & $24.6 \pm 0.25$ & $0.84 \pm 0.02$ & $76 \pm 2$ & $\begin{array}{c}15.50 \pm 0.20 \\
(15.7)\end{array}$ \\
\hline $\begin{array}{c}\text { PM6:Y6 (0.9:0.1:1.2) } \\
\text { (BTR-TE 10\%) }\end{array}$ & $24.5 \pm 0.15$ & $0.84 \pm 0.02$ & $78 \pm 2$ & $\begin{array}{c}15.95 \pm 0.15 \\
(16.1)\end{array}$ \\
\hline $\begin{array}{l}\text { PM6:Y6 (0.9:0.1:1.2) } \\
\text { (BTR-TIPS 10\%) }\end{array}$ & $24.1 \pm 0.35$ & $0.82 \pm 0.02$ & $71 \pm 3$ & $\begin{array}{c}13.7 \pm 0.30 \\
(14.0)\end{array}$ \\
\hline
\end{tabular}

Table S2. Photovoltaic device performance of ternary blend solar cells using inverted device geometry. ( $\mathrm{J}-\mathrm{V}$ parameters are calculated using 12 devices for each active layer) 
AFM images of ternary blend active layers
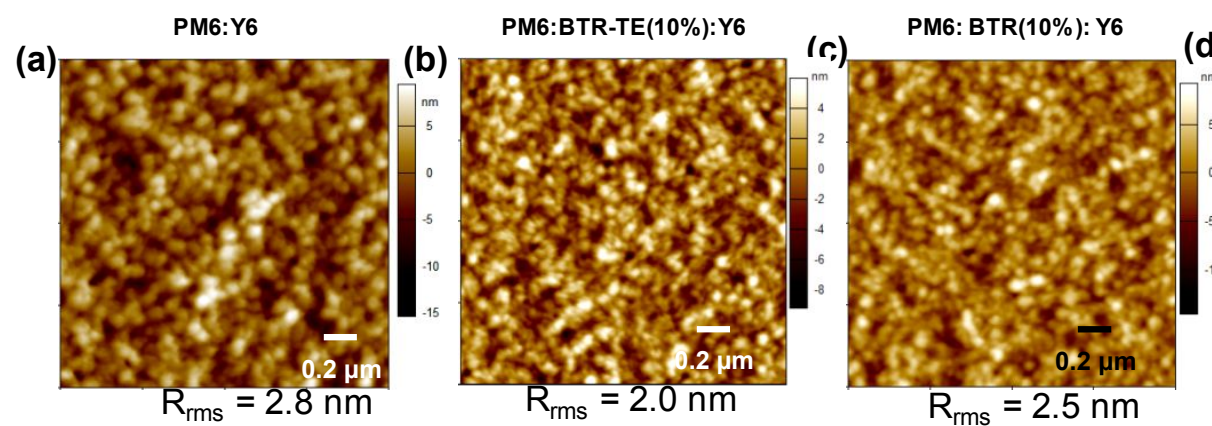

(d) PM6: BTR-TIPS(10\%): Y6
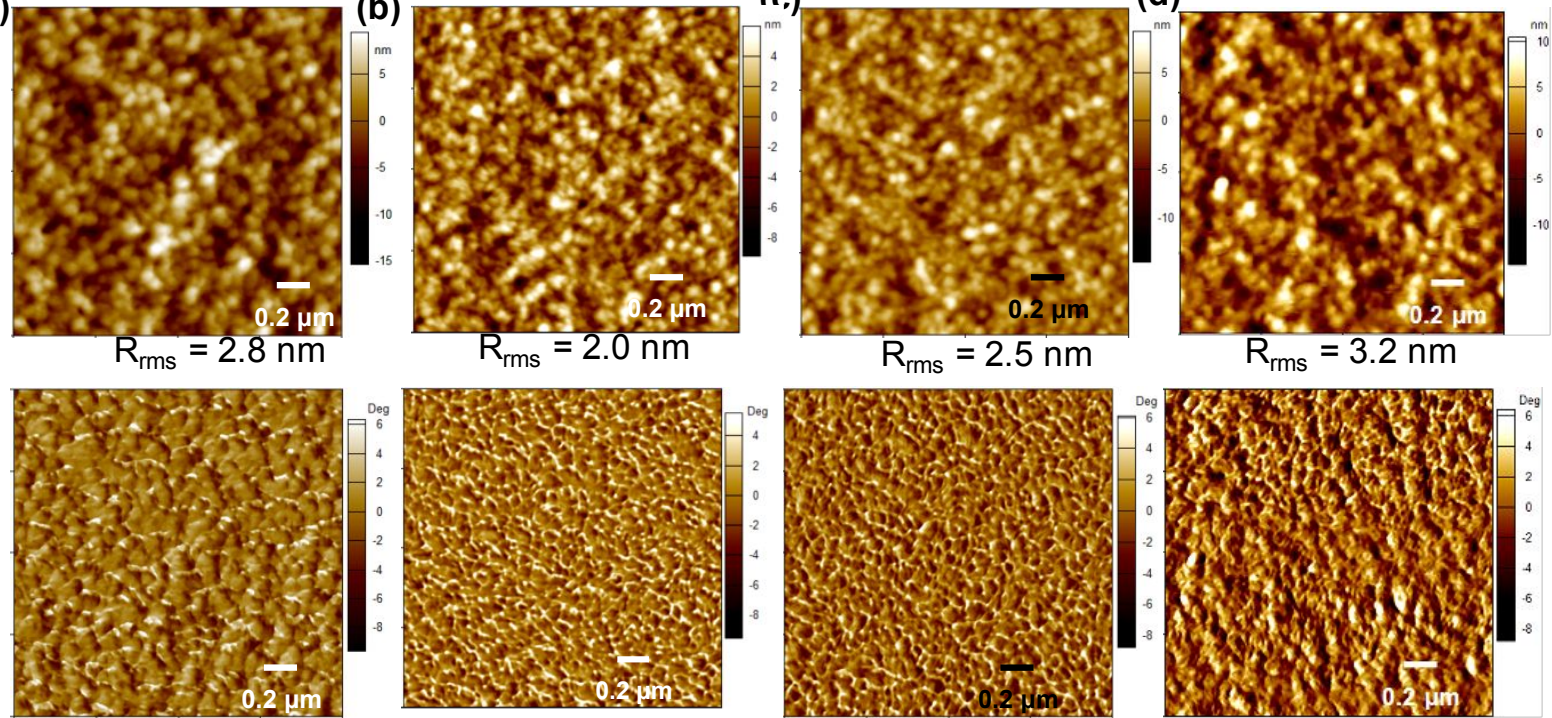

Figure S4. Tapping mode atomic force microscopy height image and phase images of (a) PM6:Y6, (b) PM6:BTR-TE(10\%):Y6, (c) PM6:BTR(10\%):Y6 and (d) PM6:BTRTIPS(10\%):Y6 surface.

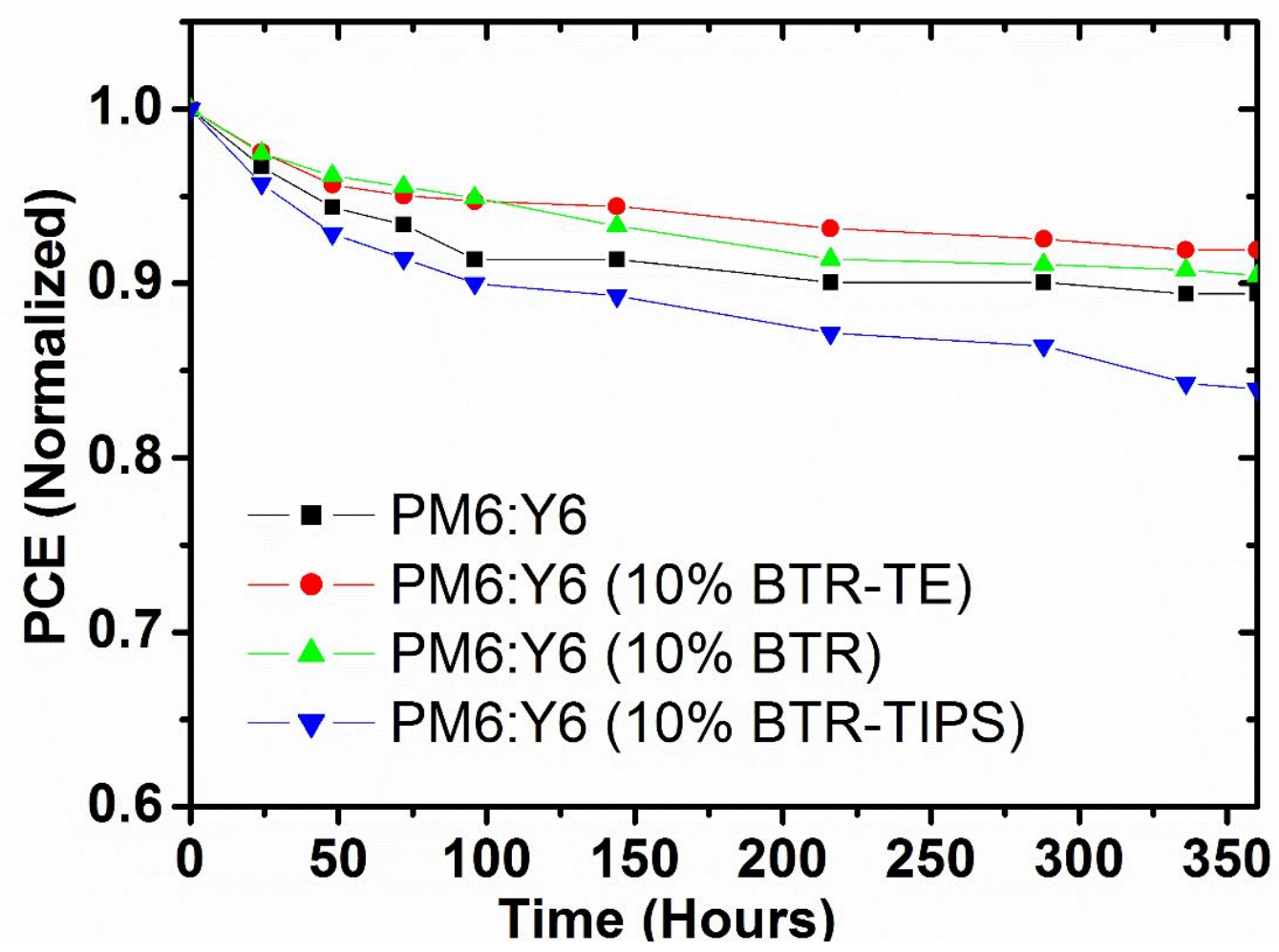

Figure S5. Stability studies of the ternary blend OPV devices. All devices are encapsulated and kept in dark between the J-V measurements. 


\section{References}

1. Kirby, N. M.; Mudie, S. T.; Hawley, A. M.; Cookson, D. J.; Mertens, H. D. T.; Cowieson, N.; Samardzic-Boban, V., A low-background-intensity focusing smallangle X-ray scattering undulator beamline. Journal of Applied Crystallography 2013, 46 (6), 1670-1680.

2. Gann, E.; Gao, X.; Di, C.-a.; McNeill, C. R., Phase Transitions and Anisotropic Thermal Expansion in High Mobility Core-expanded Naphthalene

Diimide Thin Film Transistors. Advanced Functional Materials 2014, 24 (45), 7211 7220 . 